\title{
Design and simulation of high frequency colpitts oscillator based on BJT amplifier
}

\author{
Khalid A. Humood ${ }^{1}$, Omar A. Imran², Adnan M. Taha ${ }^{3}$ \\ ${ }^{1,3}$ Department of Electronic Engineering, College of Engineering, University of Diyala, Iraq \\ ${ }^{2}$ Department of Chemical Engineering, College of Engineering, University of Diyala, Iraq
}

\begin{tabular}{l} 
Article Info \\
\hline Article history: \\
Received Feb 6, 2019 \\
Revised Aug 2, 2019 \\
Accepted Aug 29, 2019 \\
\hline
\end{tabular}

Keywords:

BJT

Colpitts oscillator

LC

$\mathrm{RF}$

\begin{abstract}
Frequency oscillator is one of the basic devices that can be used in most electrical, electronics and communications circuits and systems. There are many types of oscillators depending on frequency range used in an application such as audio, radio and microwave. The needed was appeared to use high and very high frequencies to make the rapid development of advanced technology Colpitts oscillator is one of the most common types of oscillator, it can be used for radio frequency (RF), that its output signal is often utilized at the basic of a wireless communication system in most application. In this research, a Colpitts oscillator is comprised from a bipolar junction transistor (BJT) amplifier with LC tank. This design is carrying out with a known Barkhausen criterion for oscillation. Firstly, is carried out using theoretical calculation. The secondary is carried out using simulation (Multisim 13). All the obtained result from the above two approaches are 10 $\mathrm{MHz}$ and $9.745 \mathrm{MHz}$ respectively. This result is seen to be very encouraging.
\end{abstract}

Copyright $(2020$ Institute of Advanced Engineering and Science. All rights reserved.

\section{Corresponding Author:}

Khalid A. Humood,

Department of Electronic Engineering,

College of Engineering, University of Diyala,

Baquba, Diyala Province, Iraq.

Email: humoodkhalid@engineering.uodiyala.edu.iq, humoodkhalid@gmail.com

\section{INTRODUCTION}

Frequency oscillator can be considered as an electronic oscillator that is produce a repetitive signal by converting DC voltage power supply to AC voltage signal with desired frequency. It is periodic signal of sinusoidal and non-sinusoidal shape at certain frequency and certain amplitude without any external input signal [1, 2]. Electronic oscillator can be described as two main types, the non-liner oscillator and liner oscillator. Non-liner oscillator produce a non-sinusoidal waveforms, such as, saw tooth or triangle waveform [3, 4]. Its circuit comprised an energy storage component, along with a non-liner switching circuit [5]. Liner oscillators produce sinusoidal waveform, there are two types of linear oscillator, the negative resistance oscillator and feedback oscillator. Negative resistance oscillator is based around a component which exhibits negative resistance [6]. It is used for magnetron tube and also for certain type of diode such as impact diode $[5,7]$.

Feedback oscillator is based on positive feedback which involves returning part of output signal to the input of oscillator in such as a way that it feed itself. This type of oscillator consist of a transistor amplifier or operation amplifier to obtain the required voltage amplification and feedback network to obtain the angle difference $(\Phi)$ and attenuation $(\mathrm{B}=\mathrm{Vf} / \mathrm{Vo})$. This type of oscillator is used to generate the sinusoidal voltage signal with the desired frequency. The electronic oscillator in general must satisfied Barkhausen criterion for oscillation. These criteria are firstly the angle (phase shift) between input and output must be equal $0^{\circ}$ or $360^{\circ}$, secondly the value of absolute loop gain is equal unity. There are many types of feedback oscillator circuit, such as the RC phase shift oscillator, LC oscillator and crystal oscillator. Three types of RC 
phase shift oscillators that are produce sinusoidal output such as Wien bridge oscillator, phase shift oscillator and twin T oscillator. Generally RC phase shift oscillator are used for frequency up to about $1 \mathrm{MHz}$. These oscillators can be used in many applications such as clock generation for digital electronics, switching waveform for switch mode power supply. Wien bridge oscillator is mostly used for about $1 \mathrm{MHz}$ range [8]. LC oscillator can be used for high frequency in most applications of electronic and communication circuits and systems $[9,10]$. There are different types of these oscillator such as Colpitts oscillator Hartley oscillator, Clap oscillator, Armstrong oscillator and Crystal controlled oscillator [5, 11]. The problem stetmant in the design of Collpits oscillator is that most of the present journal articals such as [12-14] also textbooks such as $[15,16]$, used the formula.

$$
\mathrm{f}_{\mathrm{o}}=\frac{1}{2 \pi \sqrt{L C_{T}}} \text { of Collpits oscillater. This is approximatet formula, which leads to ambiguity and }
$$
approximate results especially with Colpitts oscillator based BJT. The problem solution, in the following Section of the work is the new exact formula of natural frequency $\mathrm{f}_{\mathrm{o}}=\frac{1}{2 \pi \sqrt{L C_{T}}} \sqrt{\frac{Q_{f}^{2}-1}{Q_{f}^{2}}}$ of Collpits oscillator has been derivetave as novel exact formula. This new exact formula is derived and used in this paper for removing the ambiguite that why ther are different results appear between theortical, simulation and practical implementation many present article such as [17-19]. Still use approximate formula of natural frequency $\left(\mathrm{f}_{\mathrm{o}}=\frac{1}{2 \pi \sqrt{L C_{T}}}\right)$ of Collpits oscillator as exact formula.

\section{RESEARCH METHOD}

As previously explained the condition of oscillator are the amplitude condition, that loop gain (AB) equal -1 and phase condition, is equal $360^{\circ}$. If $\mathrm{BA}=-1$, then the closed loop gain ( $\mathrm{AF}$ ) as indicated in (1), goes to infinity, this mean that there is output without any input [20].

$$
\mathrm{AF}=\frac{1}{1+B A}
$$

Where:

AF : closed loop gain,

BA : loop gain.

The total phase shift produced by the forward amplifier (A) and the phase shift of feedback network (B) must be $0^{\circ}$ or $360^{\circ}$. That mean the forward amplifier (A) produce $180^{\circ}$ (inverting), the B give $180^{\circ}$, or both of them should give zero phase shift, i.e. the forward amplifier is non-inverting [21]. In this design BJT is used as npn common emitter inverting amplifier with LC tank in positive feedback network. Also the voltage divider biasing is used to obtain correct operating point in order to make the transistor work in active region condition satisfied. AC analysis of the circuit is done so that the magnitude of gain and phase shift can be calculate which required for oscillation obtained [15].

\subsection{Biasing of BJT transistor}

In order to make proper biasing of transistor that used as an amplifier in the proposed design. The biasing of the BJT lead to choose the correct operating point to make the amplifier produce output voltage signal. There are many methods to get biasing of transistor such as fixed bias, voltage divider, emitter bias, collector bias and self-bias. In this design, voltage divider method as shown in Figure 1, is used because it has many advantage, such as good stability, the amplitude is not depending on change of $\beta$ or resistors and easy control for biasing current. From theory of calculation of biasing resistors, there are some approximation can be used to reduce the steps of calculations [13].

$$
\begin{aligned}
& \mathrm{R}_{2} \leq \frac{\beta \mathrm{RE}}{10} \\
& \mathrm{I}_{1}>10 \mathrm{I}_{\mathrm{B}}
\end{aligned}
$$




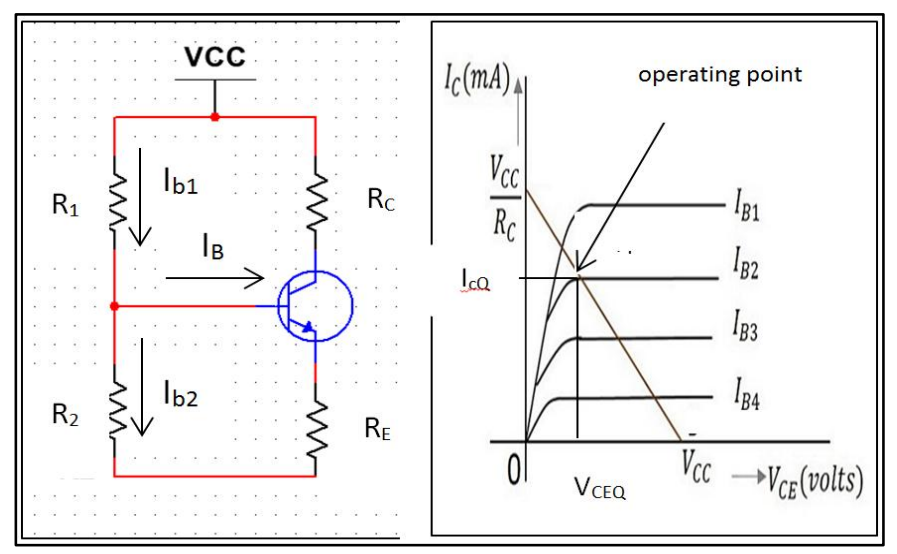

Figure 1. Voltage divider biasing

Figure 1 shows the demonstration, of voltage divider biasing that used to obtain the correct operating point, so that the values of $R_{1}, R_{2}, R_{C}$ and $R_{E}$ can be calculated. There are many steps must be done to get good biasing of the transistor, if the biasing is bad or not correct the design will not work, so that keep operating point $\left(\mathrm{Q}_{\mathrm{p}}\right)$ in the middle of active region as shown in Figure 1, using the given rules of some parameters and apply the circuit rules of biasing in design done for npn BJT type BC 548A. The steps of calculating the resistors of the transistor is done as follows: from data sheet of BC 548A, it is given that:

$$
\begin{aligned}
& \mathrm{VBE}=0.65 \mathrm{v} \\
& \mathrm{VCE}=0.5 \mathrm{v} \\
& (\mathrm{hfe}) \beta_{\min }=110,(\mathrm{hfe}) \beta_{\max }=220 \\
& \mathrm{VCE}(\mathrm{sat})=0.6 \mathrm{v} \\
& \mathrm{f}_{\mathrm{T}}=100 \mathrm{MHz} \\
& \mathrm{hfe}\left(\beta_{\mathrm{dc}}\right)_{\text {average }}=\sqrt{\mathrm{hfe}(\max ) \cdot \mathrm{hfe}(\mathrm{min} .)} \\
& =\sqrt{110 \times 220} \cong 156
\end{aligned}
$$

From (2), $R_{2}=\beta R_{E} / 10$

$$
\begin{aligned}
& \text { assume } \mathrm{R}_{\mathrm{E}}=1 \mathrm{k} \Omega, \therefore \mathrm{R}_{2} \leq \frac{156 \times 1000}{10} \\
& \therefore \mathrm{R}_{2} \leq 15.6 \mathrm{k} \Omega
\end{aligned}
$$

To satisfy this equality can be choosing $\mathrm{R}_{2}$ equal $4 \mathrm{k} \Omega$

$$
\mathrm{I}_{\mathrm{b} 1}-\mathrm{I}_{\mathrm{b} 2}=\mathrm{I}_{\mathrm{B}}
$$

Let these is a known condition that $\mathrm{I}_{\mathrm{b} 1}>10 \mathrm{I}_{\mathrm{B}}$

$$
\mathrm{I}_{\mathrm{b} 1}=48 \mathrm{I}_{\mathrm{B}}
$$

From (4) \& (5) get

$$
\begin{aligned}
& 48 I_{B}-I_{b 2}=I_{B} \\
& I_{b 2}=\left(V B E+(\beta+1) I_{B} R_{E}\right) / R_{2}
\end{aligned}
$$

$\mathrm{VBE}=0.65 \mathrm{v}$ from data sheet

$$
\therefore \mathrm{I}_{\mathrm{b} 2}=\frac{0.65+(156+1) \mathrm{I}_{B} \times 1000}{4000}=0.163+39 \mathrm{I}_{\mathrm{B}}
$$


By sub. (8) in (6)

$$
\begin{aligned}
& 48 \mathrm{I}_{\mathrm{B}}-0.163 \times 10^{-3}-39 \mathrm{I}_{\mathrm{B}}=\mathrm{I}_{\mathrm{B}} \\
& 48 \mathrm{I}_{\mathrm{B}}-39 \mathrm{I}_{\mathrm{B}}-\mathrm{I}_{\mathrm{B}}=0.163 \mathrm{~mA} \\
& 8 \mathrm{I}_{\mathrm{B}}=0.163 \mathrm{~mA} \\
& \mathrm{I}_{\mathrm{B}}=0.0204 \mathrm{~mA}, \mathrm{I}_{\mathrm{B}}=20.4 \mu \mathrm{A} \\
& \mathrm{I}_{\mathrm{b} 1}=48 \mathrm{I}_{\mathrm{B}}=48 \times 20.4 \mu \mathrm{A}=0.0979 \mathrm{~mA} \\
& \mathrm{Ic}=\beta \mathrm{I}_{\mathrm{B}}=156 \times 20.4 \mu \mathrm{A} \approx 3.2 \mathrm{~mA}
\end{aligned}
$$

By applying KVL on base circuit of Figure 2 so that:

$$
\begin{aligned}
& \mathrm{R}_{1}=\frac{\mathrm{Vcc}-\mathrm{VBE}-\mathrm{I}_{B}(\beta+1) \mathrm{R}_{E}}{\mathrm{I}_{b 1}} \\
& =\frac{12-0.65-0.0204 \times 10-3(156+1) \times 1 \mathrm{k} \Omega}{48 \mathrm{I}_{B}} \\
& =\frac{8.15}{0.9792 \mathrm{~mA}} \\
& \therefore \mathrm{R}_{1}=8.323 \mathrm{k} \Omega \approx 8.4 \mathrm{k} \Omega
\end{aligned}
$$

Applying KVL on collector circuit of Figure 1 so that:

$$
\begin{aligned}
& \mathrm{VCE}=\mathrm{Vcc}-\mathrm{Ic}\left(\mathrm{Rc}+\mathrm{R}_{\mathrm{E}}\right) \\
& \mathrm{VCE}=3.5 \mathrm{v} \\
& 3.5=12-\beta \mathrm{I}_{\mathrm{B}}\left(\mathrm{Rc}+\mathrm{R}_{\mathrm{E}}\right) \\
& \beta \mathrm{I}_{\mathrm{B}}\left(\mathrm{Rc}+\mathrm{R}_{\mathrm{E}}\right)=12-3.5 \\
& 156 \times 0.0204 \times 10^{-3}(\mathrm{Rc}+1 \mathrm{k} \Omega)=12-3.5 \\
& 3.1824+3.1824 \mathrm{Rc} \times 10^{-3}=8.5 \\
& 3.1824 \mathrm{Rc} \times 10^{-3}=8.5-3.1824=5.3176 \\
& \therefore \mathrm{Rc}=\frac{5.3176}{3.1824 \times 10-3}=1.6709 \mathrm{k} \Omega
\end{aligned}
$$

Finally, the complete circuit of proposal design is clear in Figure 3. This circuit contain biasing parameters $\left(R_{1}, R_{2}, R c\right.$ and $\left.R_{E}\right)$ also capacitors such as $C_{s} \& C_{c}$ for DC coupling, $C_{e}$ used with resistance $R_{E}$ to get amplify voltage. $\mathrm{LC}$ tank is used to complete oscillation conditions.

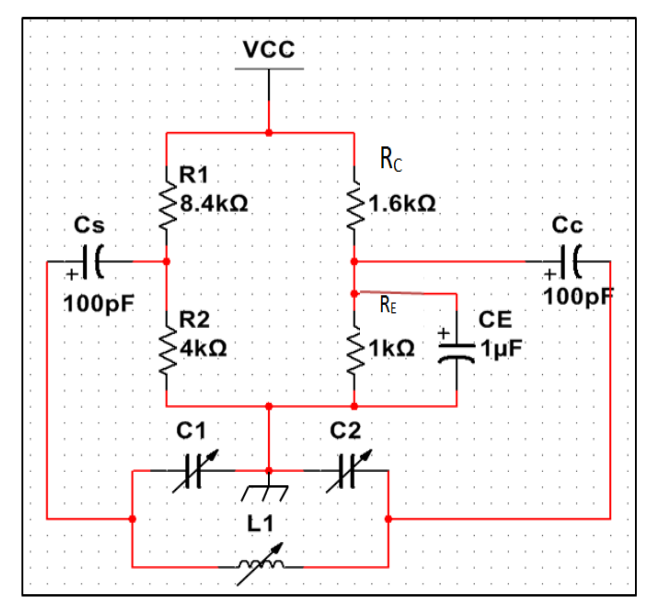

Figure 2. Theoretical circuit diagram of the proposed design

\subsection{AC equivalent circuit of the design}

To obtain the amplification factor of the electronic circuit of the proposed design, that can be lead to verify the Barkhausen criteria. Figure 3 shows the ac small signal equivalent circuit for the circuit diagram shown in Figure 2. It is can be used for low or high frequency equivalent circuit because it is used to calculate, the gain of the common emitter BJT amplifier [16, 22, 23]. 


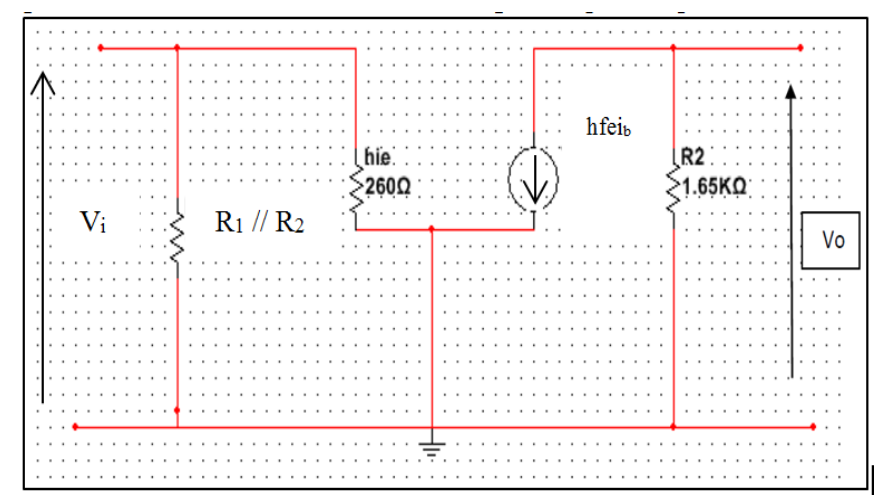

Figure 3. Low frequency equivalent circuit

$$
\begin{aligned}
& \mathrm{I}_{\mathrm{B}} \approx 0.0204 \mathrm{~mA} \\
& r \bar{e}=\frac{26 \mathrm{mv}}{\mathrm{IE}}, \mathrm{I}_{\mathrm{E}}=(\mathrm{hfe}+1) \mathrm{I}_{\mathrm{B}}=3.2 \mathrm{~mA} \\
& \text { Where: } r \bar{e} \text { equivalent ac resistance } \\
& r \bar{e}=\frac{26 \mathrm{mv}}{3.2 \mathrm{~mA}}=8.125 \Omega \\
& \text { hie }=\mathrm{hfe} r \bar{e}=156 \times 8.125 \approx 1.268 \mathrm{~K} \Omega \\
& \mathrm{R}_{\mathrm{B}}=\frac{8.4 \times 4}{8.4+4}=2.7096 \mathrm{~K} \Omega \approx 2.71 \mathrm{~K} \Omega \\
& \mathrm{R}_{\text {in }}=\mathrm{R}_{\mathrm{B}} / / \text { hie }=2.71 \mathrm{~K} \Omega / / 1.268 \mathrm{~K} \Omega=0.836 \mathrm{~K} \Omega \\
& \mathrm{Av}=\frac{-\mathrm{Vo}}{\mathrm{Vi}}=\left(-\mathrm{hfe} \mathrm{i}_{\mathrm{b}} \mathrm{R}_{\mathrm{C}} / \mathrm{i}_{\mathrm{b}} \mathrm{R}_{\text {in }}\right)=\frac{-156 \times 1.6 \mathrm{~K}}{0.836 \mathrm{~K}} \\
& =-289.22 \approx-289 \\
& |\mathrm{~A}|=|\mathrm{Av}|=289 \\
& |\mathrm{BA}|=1 \\
& |\mathrm{~B}|=\frac{1}{289}=0.004
\end{aligned}
$$

\subsection{Feedback techniques}

This technique is used to improve the performance of the amplifier characteristic. In the proposed design the positive feedback network is used to obtain oscillation condition to make the circuit work as oscillator. Figure 2 shows the circuit that represent the proposed design. It is clear that from the design outline the feedback used is positive to achieve the criteria of Barkhausen, that the phase shift between input and output must be zero or $360^{\circ}$ degree. As known fact that the oscillator is a device used to convert the DC voltage to AC output voltage with the desired frequency. So that must be verify the following condition the output loop gain $\mathrm{AB}$ must be greater than one slightly. In this design the gain Av (voltage gain) is calculated in Section 2.2 as $A=-h f e R_{c} / R_{\text {in }}$ for common emitter BJT amplifier.

\subsubsection{LC tank}

LC tank is used as feedback network circuit in the design. The feedback factor (B), which obtain from LC tank circuit must be verify the requirement of the criteria Barkhausen for oscillation, there requirement are the loop gain must be equal one as following:

$|\mathrm{AB}|=1$

But A has been calculated in Section 2.2 as

$$
\begin{aligned}
& |\mathrm{A}|=289 \\
& \therefore|\mathrm{B}|=\frac{1}{\mathrm{~A}} \cong 0.004
\end{aligned}
$$

Figure 4 shows the LC tank circuit diagram used for positive feedback, this circuit appears as resistance circuit at resonance and the impedance as infinity outside the terminal 1 and 2 of the LC tank. 


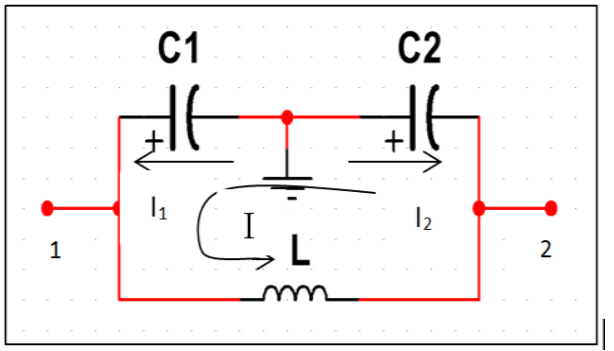

Figure 4. LC tank circuit

\subsubsection{Derivation of novel exact formula}

In order to calculate the formula of the desired frequency on the LC tank circuit that shown in Figure 4 as Figure 5 at resonance, the value of current become maximum so that the reactive impedance of the LC tank equal to zero, i.e. the inductive impedance cancels the capacitive impedance.

$$
\mathrm{C}_{\mathrm{T}}=\frac{\mathrm{C} 1 \mathrm{C} 2}{\mathrm{C} 1+\mathrm{C} 2}
$$

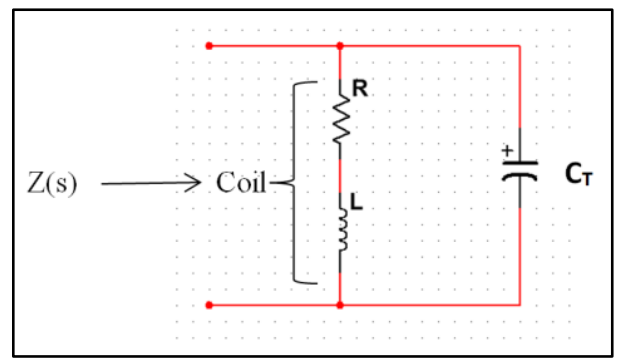

Figure 5. Equivalent LC tank circuit.

From Figure 5 calculate the following:

$$
\begin{aligned}
& \frac{1}{\mathrm{z}(\mathrm{s})}=\frac{1}{\mathrm{XC}_{T}}+\frac{1}{\mathrm{R}+\mathrm{XL}}=S C_{T}+\frac{1}{\mathrm{R}+\mathrm{SL}} \\
& =\frac{S^{2} L C_{T}+S R C_{T}+1}{\mathrm{R}+\mathrm{SL}} \\
& \frac{1}{Z(j w)}=\frac{-w^{2} L C_{T}+j w R C_{T}+1}{R+j w L}=\frac{\left(1-w^{2} L C_{T}\right)+j w R C_{T}}{R+j w L} \\
& Z(j w)=\frac{R+j w L}{\left(1-w^{2} L C_{T}\right)+j w R C_{T}} \\
& |Z(j w)|=\frac{(R+j w L)\left[\left(1-w^{2} L C_{T}\right)-j w R C_{T}\right]}{\left(1-w^{2} L C_{T}\right)+\left(w R C_{T}\right)^{2}} \\
& \frac{R-j w\left(R^{2} C_{T}+w^{2} L^{2} C_{T}-L\right)}{\left(\left(1-w^{2} L C_{T}\right)^{2}\right)+\left(w R C_{T}\right)^{2}}
\end{aligned}
$$

At resonance the imaginary part of (11) are equal to zero.

$$
\begin{aligned}
& \mathrm{jw}_{\mathrm{o}}\left(\mathrm{R}^{2} \mathrm{C}_{\mathrm{T}}+\mathrm{w}_{\mathrm{o}}{ }^{2} \mathrm{~L}^{2} \mathrm{C}_{\mathrm{T}}-\mathrm{L}\right)=0 \\
& \therefore \mathrm{R}^{2} \mathrm{C}_{\mathrm{T}}+\mathrm{w}_{\mathrm{o}}{ }^{2} \mathrm{~L}^{2} \mathrm{C}_{\mathrm{T}}-\mathrm{L}=0 \\
& \mathrm{w}_{\mathrm{o}}{ }^{2} \mathrm{~L}^{2} \mathrm{C}_{\mathrm{T}}=\mathrm{L}-\mathrm{R}^{2} \mathrm{C}_{\mathrm{T}} \\
& \therefore \mathrm{w}_{\mathrm{o}}{ }^{2}=\frac{\mathrm{L}}{L^{2} \mathrm{C}_{T}}-\frac{R^{2} C_{T}}{L^{2} \mathrm{C}} T \\
& \mathrm{w}_{\mathrm{o}}{ }^{2}=\frac{1}{L \mathrm{C}_{T}}-\frac{R^{2}}{L^{2}}, \therefore \mathrm{w}_{\mathrm{o}}=\sqrt{\frac{1}{L \mathrm{C}_{T}}-\frac{R^{2}}{L^{2}}} \\
& \mathrm{f}_{\mathrm{o}}=\frac{1}{2 \pi} \sqrt{\frac{1}{L \mathrm{C}_{T}}-\frac{R^{2}}{L^{2}}}=\frac{1}{2 \pi \sqrt{L C_{T}}} \sqrt{1-\frac{R^{2} C_{T}}{L}}
\end{aligned}
$$


The quality factor for parallel LC circuit at resonance can be written as following [24, 25].

$$
\text { Either } \mathrm{Q}_{\mathrm{f}}=\frac{W L}{R} \text { or } \mathrm{Q}_{\mathrm{f}}=\frac{1}{w R C}
$$

The (12) can be modified as following

$$
\begin{aligned}
& \mathrm{f}_{\mathrm{o}}=\frac{1}{2 \pi \sqrt{L C_{T}}} \sqrt{1-\frac{R \cdot R \cdot C_{T} w}{w \cdot L}} \\
& \text { If } \mathrm{Q}_{\mathrm{f}}=\frac{w \cdot L}{R} \\
& \text { or } \mathrm{Q}_{\mathrm{f}}=\frac{1}{w \cdot R C_{T}}
\end{aligned}
$$

Then Novel by substitute (14) and (15) in (13) getting

$$
\mathrm{f}_{\mathrm{o}}=\frac{1}{2 \pi \sqrt{L C_{T}}} \sqrt{1-\frac{1}{Q_{f}^{2}}}
$$

The exact formula of resonance frequency $\left(f_{0}\right)$ is:

$$
\mathrm{f}_{\mathrm{o}}=\frac{1}{2 \pi \sqrt{L C_{T}}} \sqrt{\frac{Q_{f}^{2}-1}{Q_{f}^{2}}}
$$

Where:

$\mathrm{f}_{\mathrm{o}}$ : resonance frequency in $\mathrm{Hz}$

$\mathrm{C}_{\mathrm{T}}$ : equivalent capacitor of $\mathrm{C}_{1} \& \mathrm{C}_{2}$ in farad

$\mathrm{L}$ : inductance in Henry

$\mathrm{Q}_{\mathrm{f}}:$ Quality factor

If $\mathrm{Q}_{\mathrm{f}} \geq 10$ the (16) of exact resonance frequency can be taken as approximate formula of resonance frequency $\left(\mathrm{f}_{\mathrm{o}}\right)$ as following:

$$
\mathrm{f}_{\mathrm{o}}=\frac{1}{2 \pi \sqrt{L C_{T}}}
$$

The (16) represent the exact expression of resonance frequency of LC tank circuit with the loading effect. In (17), quality factor $\left(Q_{f}\right)$ is taken as very high value because the value of self-resistor of inductive is very small and the loading effect is neglected so that the following term is equal approximately one as follows:

$$
\left(\mathrm{Q}_{\mathrm{f}}^{2}-1 / \mathrm{Q}_{\mathrm{f}}^{2}\right)^{0.5} \approx 1
$$

In our proposed design the loading effect can't be neglected because the value of input impedance of BJT amplifier is small. So that the quality factor $\left(Q_{f}\right)$ become less than 10 . i.e the term $\left(\left(Q_{f}^{2}-1\right) / Q_{f}^{2}\right)^{0.5}$ must be taken in account. Therefore, the resonance frequency is taken as in (16) so that the resonance frequency significantly smaller than the approximate value as in (17).

\subsubsection{Feedback factor (B)}

As indicate in Section 2.3.1 that LC tank is the circuit of the positive feedback network. Figure 2 shows the circuit diagram of the proposed design. As shown in this figure the output voltage signal transfer to the LC tank through the capacitor Cc. The output voltage $\left(\mathrm{V}_{\mathrm{o}}\right)$ of the circuit is created at $\mathrm{C}_{2}$ of the LC tank circuit. Also the feedback voltage signal is created at $\mathrm{C}_{1}$ of the $\mathrm{LC}$ tank circuit, and had been gone the input circuit through the capacitor Cs. The ratio of $\frac{V f}{V o}$ is less than one so that the value of $\mathrm{C}_{2}$ must be less than or equal to $\frac{1}{20}$ of $\mathrm{C}_{1}$. 
Therefore:

$$
\begin{aligned}
& \mathrm{B}=\frac{\mathrm{Vf}}{\mathrm{Vo}}=\frac{\mathrm{I} * \mathrm{XC} 1}{\mathrm{I} * \mathrm{XC} 2}=\frac{-\mathrm{I} * \frac{1}{\mathrm{WC} 1}}{\mathrm{I} * \frac{1}{\mathrm{WC} 2}}=\frac{-\mathrm{C} 2}{\mathrm{C} 1} \\
& \therefore|\mathrm{B}|=\frac{\mathrm{C} 2}{\mathrm{C} 1}, \therefore|\mathrm{A}|=\frac{\mathrm{C} 1}{\mathrm{C} 2}
\end{aligned}
$$

The negative sign mean that there is phase shift of 180 degree because the capacitors $\mathrm{C}_{1}$ and $\mathrm{C}_{2}$ are connected as center tap as shown in Figure 4 so that the phase shift is 180 degree. Therefore, the total phase shift of the proposed circuit is equal 360 degrees [(180 from common emitter BJT) and 180 degree of the center tap configuration of capacitor LC tank]. From the above statement the parameters A, B are calculated. These parameters can be used to control the output voltage in frequency and amplitude by choosing its value according to ratio of $\mathrm{C}_{1} / \mathrm{C}_{2}$. The value of forward gain (A) and feedback factor (B) with keep that the value of $C_{1}$ must be larger than $C_{2}$ by reasonable factor. Keeping the value of $L$ as low as possible for the fabrication technology limitation as well as to minimize the effect of frequency of high parasitic elements of high frequency to get good amplification and stability of the amplifier as indicated in Section 2.2 that $\mathrm{A}=-$ hfe $\left(\mathrm{RC} / \mathrm{R}_{\mathrm{in}}\right)$.

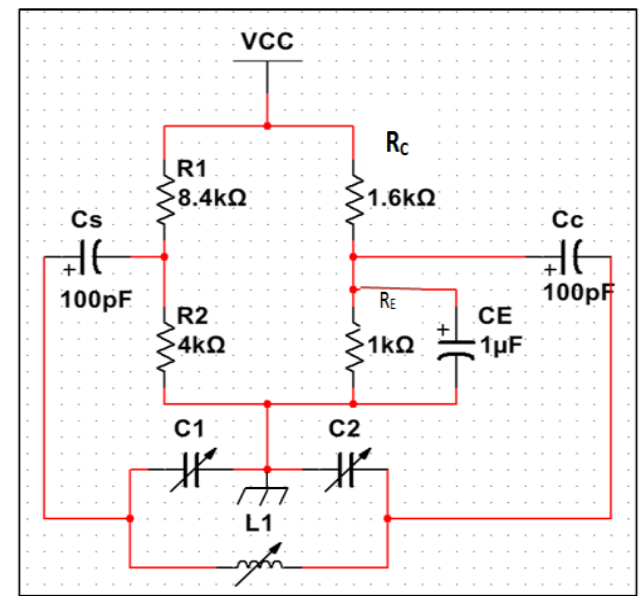

Figure 6. Simulation circuit diagram of proposed design

\section{SIMULATION OF PROPOSED DESIGN}

In this paper design of high frequency of Colpitts oscillator which is consist from common emitter BJT amplifier with LC tank as positive feedback is simulated using multisim technique. The circuit diagram of the proposed design is shown in Figure 6. It is achieved in Section 2 with all required parameters are calculated. Then it is simulated using multisim 13. The proposed design shown in Figure 6 is simulated to calculate Table (1) which shows the output signal voltages for different variable values of $\mathrm{C}_{1}, \mathrm{C}_{2}, \mathrm{~L}$ and $\mathrm{B}$ with the desired output frequency according to the forward gain of the common emitter BJT amplifier. There are many output signal voltages obtained with different frequencies as decided by choosing the value of $\mathrm{C}_{1}$, $\mathrm{C}_{2}$ and $\mathrm{L}$ with limitation of the value of $\mathrm{Av} \& \mathrm{~B}$. It is clear that from the results obtained as shown in Table 1 that these results are different from that calculated in Section 2.2, because the values calculated in theoretical calculation which done using approximate expression formula. Also the effect of load resistance of input impedance of common emitter BJT amplifier of the design is small and this effect on quality factor $\left(\mathrm{Q}_{\mathrm{f}}\right)$ to become very smaller than 10 so that according to (16) the value of resonance frequency become small significantly than that obtain early. There are also the effect of parasitic elements these effect to reduce the oscillating frequency.

\section{RESULTS}

The results of output simulated voltages and the theoretical calculations for resonance frequencies for high frequency Colpitts oscillator circuit are shown in Table 1. This table shows resonance frequencies of simulated output signals and theoretical calculations with the related variable value of $\mathrm{C}_{1}, \mathrm{C}_{2}, \mathrm{~L}$, and $\mathrm{B}$ for the high frequency Colpitts oscillator. The values of coupling capacitor $\mathrm{Cc}, \mathrm{C}_{\mathrm{s}}$ are $0.1 \mathrm{nf}$ for each and 
capacitor $\mathrm{C}_{\mathrm{E}}$ equal to $0.5 \mu \mathrm{f}$. Figure 7 shows the more reasonable resonance frequency of the output simulated voltage signal. It is clear that the value of resonance frequency is the more acceptable compared with other results because the difference between the theoretical and simulated value is small. This results make the design to be near to be acceptable and can be implemented practically. It is clear that from the results indicated above that there are different values of frequencies of output voltage signal, which are simulated for different variable of $\mathrm{C}_{1}, \mathrm{C}_{2}$, and $\mathrm{L}$ compared with that are theoretical calculated these difference happen due to many factors such as temperature, stability, biasing, type of transistor. But the most signified one is that the formula that used for finding the frequency of resonance of LC tank, it is approximant approach where is the assuming quality factor $\left(\mathrm{Q}_{\mathrm{f}}\right)$ is very high so that all calculations of finding resonance frequency are done using (17). In this equation the term

$\left(\left(\mathrm{Q}_{\mathrm{f}-1)}^{2}\right) / \mathrm{Q}_{\mathrm{f}}^{2}\right)^{0.5}$ is neglected. So that the real results can be obtain if the calculation are done using (16). So that the results which obtained from the simulation are more near to the reality, because the results are obtained with consider the effect of quality factor $\left(\mathrm{Q}_{\mathrm{f}}\right)$ because of the loading effect of BJT amplifier input impedance which it is small, therefore the quality factor $\left(Q_{f}\right)$ is become very lower than that used in theoretical calculations. Therefore, the output values of these output voltage signals are significantly smaller than that theoretical calculation. As show in Figure 7 that the result of resonance frequency of output voltage signal of the final proposed design is equal to $9.745 \mathrm{MHz}$ if compared with the theoretical calculated $10 \mathrm{MHz}$ it is seen to be encouraging.

Table 1. Results of output calculated and simulated voltages

\begin{tabular}{cccccccc}
\hline $\mathrm{C}_{1} \mathrm{pf}$ & $\mathrm{C}_{2} \mathrm{pf}$ & $\mathrm{C}_{\mathrm{T}} \mathrm{pf}$ & $\mathrm{L}$ & $\mathrm{B}$ & \multicolumn{2}{c}{ Resonance frequency } & o/p signal shape frequency \\
& & & & & Theoretical frequency & Simulation frequency & \\
\hline 163 & 30 & 25.336 & $10 \mu \mathrm{H}$ & 0.184 & $10 \mathrm{MHz}$ & $9.745 \mathrm{MHz}$ & Figure 7 \\
266 & 28 & 25.33 & $10 \mu \mathrm{H}$ & 0.105 & $10 \mathrm{MHz}$ & $9.62 \mathrm{MHz}$ & Figure 8 \\
266 & 28 & 25.33 & $400 \mathrm{nH}$ & 0.105 & $50 \mathrm{MHz}$ & $45.26 \mathrm{MHz}$ & Figure 9 \\
266 & 28 & 25.33 & $1.6 \mu \mathrm{H}$ & 0.105 & $25 \mathrm{MHz}$ & $23.14 \mathrm{MHz}$ & Figure 10 \\
\hline
\end{tabular}

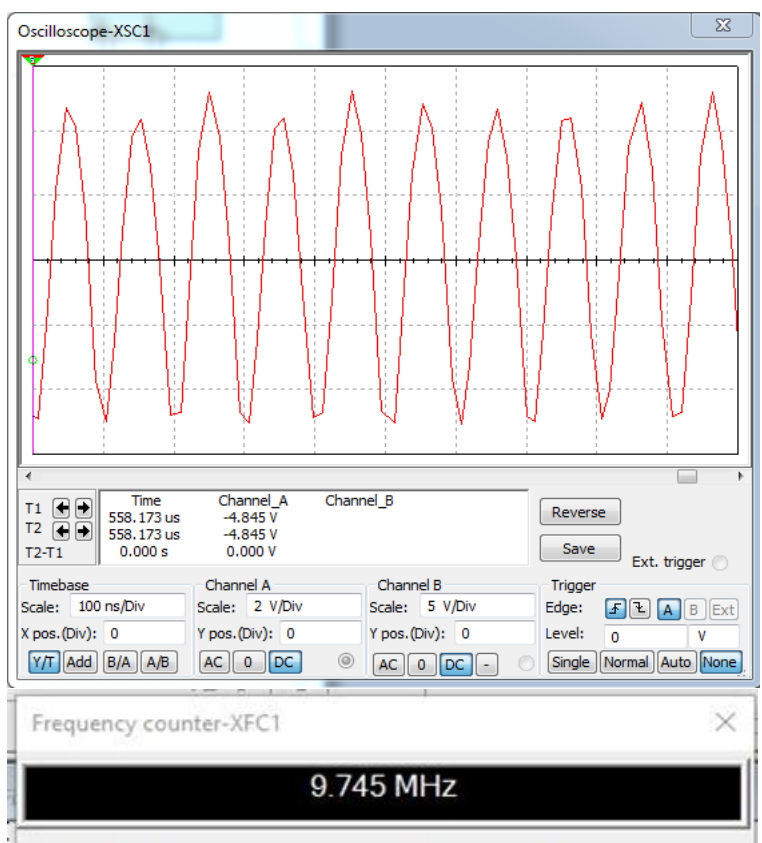

Figure 7. Shape and resonance frequency of simulated o/p signal

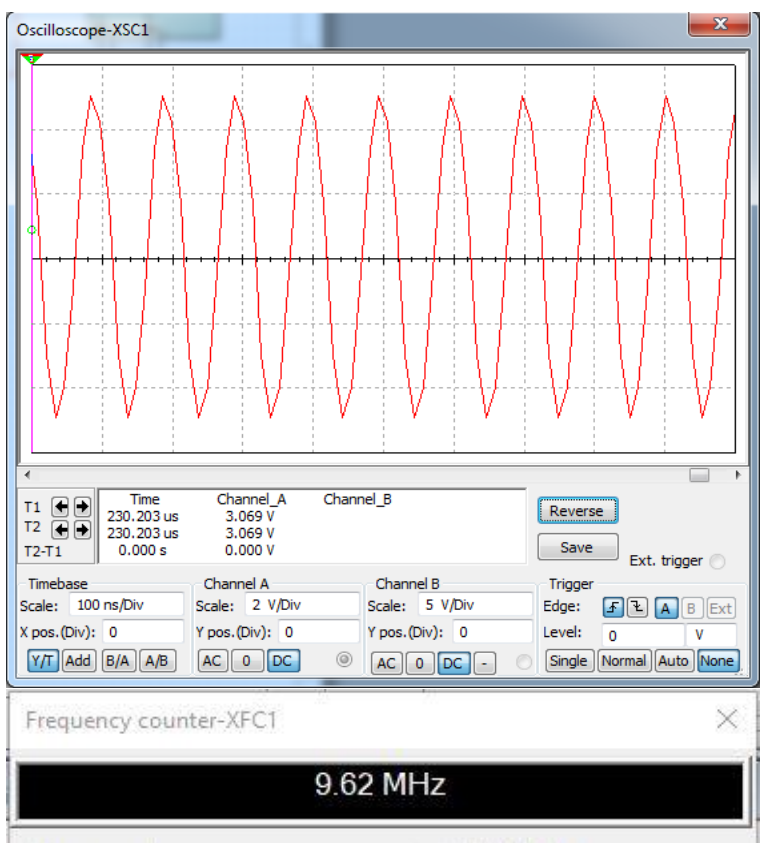

Figure 8. Shape and resonance frequency of simulated o/p signal 


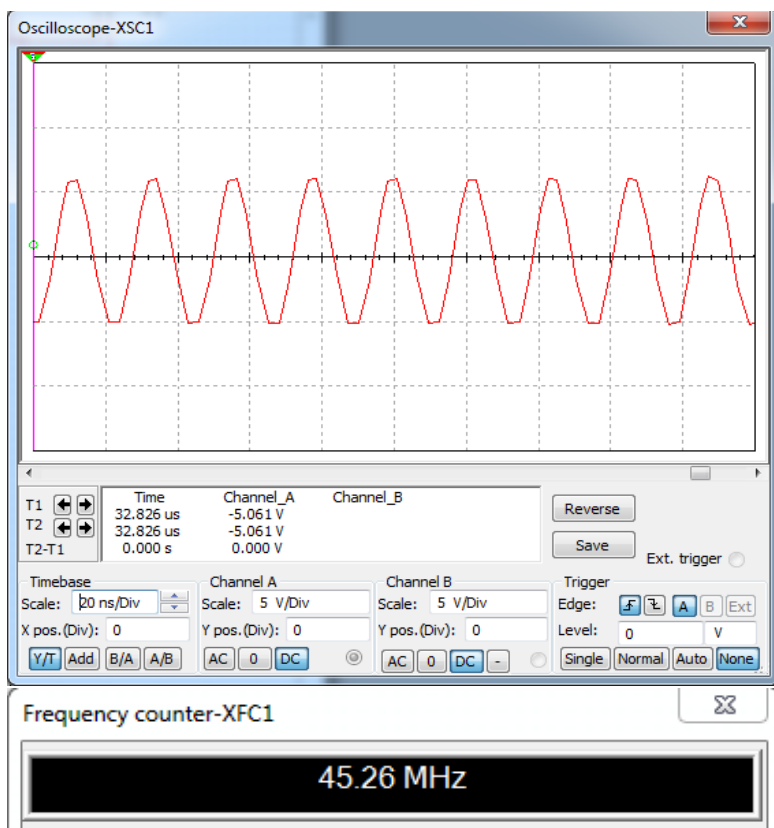

Figure 9. Shape \& resonance frequency of simulated $\mathrm{o} / \mathrm{p}$ signal

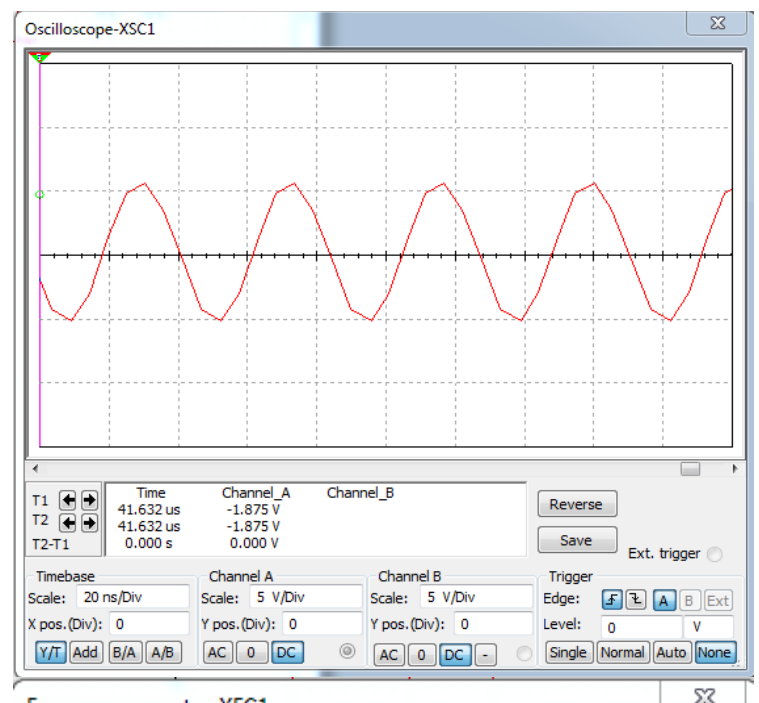

Frequency counter-XFC1

\section{3. $149 \mathrm{MHz}$}

Figure 10. Shape \& resonance frequency of simulated o/p signal

\section{CONCLUSIONS}

In this research the high frequency Colpitts oscillator has been done. The BJT used in this design has an improved properties made it suitable to making design can be done for high frequency oscillator. It is clear that there is significant difference between theoretical and simulated vales of resonant frequency output signal. This is appearing because the input impedance of the BJT amplifier which act as a load on the resonant feedback circuit and reduce the $\mathrm{Q}_{\mathrm{f}}$ of the circuit. The resonant frequency of a parallel resonant depend on the $\mathrm{Q}_{\mathrm{f}}$ according to the Novel exact formula.

\section{REFERENCES}

[1] Khalid Awaad Humood, Adham Hadi Saleh, Wurod Qasim Mohamed, "Design and Implementation of Op-AmpRC Sine Wave Oscillator,” Diyala Journal of Engineering Sciences, vol. 08, no. 01, pp. 89-901, Mar 2015.

[2] Khalid Awaad Humood, Adham Hadi Saleh, Wurod Qasim Mohammed, "Design and Simulation of Op-Amp-RC Sine Wave Oscillator,” Bulgarian journal for Engineering Design, no. 24, Oct 2014.

[3] Julius Han Loong Teo, Noor Alia Nor Hashim, Azrul Ghazali, Farzena Azlee Hamid, "Ring Oscillator Physical Unclonable Function Using Sequential Ring Oscillator Pairs for More Challenge-Response-Pairs," Indonesian Journal of Electrical Engineering and Computer Scince (IJEECS), vol. 13, no. 3, pp. 892-901, Mar 2019.

[4] Noor Alia nor Hashim, Julius Teo Han Loong, Azrul Ghazali, Farzena Azlee Hamid, "Memristor Based Ring Oscillators True Random Number Generator with Different Window Functions for Applications in Cryptography," Indonesian Journal of Electrical Engineering and Computer Scince (IJEECS), vol. 14, no. 1, pp. 201-209, 2019.

[5] Khalid Awaad Humood, Wurod Qasim and Farah Hammed, "Design Analog RC-Active 2nd-Order Audio Low Pass Filter (LPF)," First Engineering Scientific Conference College of Engineering-University of Diyala, pp. 485-498, Dec 2010.

[6] Ayoub Malki, Larbi El Abdellaoui, Jamal Zbitou, A. Errkik, A. Tajmouati, Mohamed Latrach, "A Novel Design of Voltage Controlled Oscillator by Using the Method of Negative Resistance ," International Journal of Electrical and Computer Engineering (IJECE), vol. 8, no. 6, pp. 4496 - 4504, Dec 2018.

[7] Daniel Richard Brennan, BEng (Hons.), "Silicon Carbide Technology for Extreme Environments," a thesis submitted to the faculty of science, agriculture and engineering for the degree of doctor of philosophy, MSc, School of Electrical and Electronic Engineering, Newcastle University, United Kingdom, March 2015.

[8] D. A. Hadi, A. Z. Jidin, N. Ab Wahab, Madiha Z., Nurliyana Abd Mutalib, Siti Halma Johari, Suziana Ahmed, M. Nuzaimah, "CMOS Ring Oscillator Delay Cell Performance A Comparative Study," International Journal of Electrical and Computer Engineering (IJECE), vol. 9, no. 3, pp. 1757 - 1764, Jun 2019.

[9] Nam-Jin Oh, "Single-Stage Quadrature LMVs," International Journal of Electrical and Computer Engineering (IJECE), vol. 8, no. 1, pp. 124 - 132, Feb 2018.

[10] Kasim K. Abdalla, "New Tow Simple Sinusoidal Generators with Four 45o Phase Shifted Voltage Outputs Using Single FDCCII and Grounded Components," International Journal of Electrical and Computer Engineering (IJECE), vol. 8, no. 6, pp. 5080 - 5088, Dec 2018. 
[11] Rhea, Randallw., Oscillator Design and Computer Simulation, Noble Publishing Corp. Atlanta, 2nd edition, 1995.

[12] Ming-Chou Liao, Gong Chen, Jia - Yi Sze and Cheng - Chung Sung, "Adaptive Control for Promoting Synchronization Design of Chaotic Colpitts Oscillator," Journal of the Chinese Institute of Engineers, vol. 31, no. 4 , pp. $703-707,2008$.

[13] Marian K. Kazimierczuk, Dakshina Murthy-Bellur, "Loop Gain of the Common - Drain Colpitts Oscillator," INTL Journal of Electronics and Telecommunications, vol. 56, no. 4, pp. 423 - 426, 2010.

[14] Hongmian Deng, Dongping Wang, "A Memristor-Based Colpitts Like Oscillator," 2016 International Conference on Information Engineering and Communcations Technology (IECT 2016), 2016.

[15] Thomas F. Schubert, Jr. and Ernest M. Kim, Fundamentals of Electronics: Book 4 Oscillator and Advanced Electronics Topics, by Margan \& Claypool, 2016.

[16] Rebert L. Boylested \& Louis Nashelsky, Electronic Devices and Circuit Theory, International Edition, Ninth Edition, by pearson Education, 2006.

[17] Juan L. Mata-Machuca, Rafael Martinez-Guerra, "Asymptotic Synchronization of The Colpitts Oscillator," Computer and Mathematics with Applications, vol. 63, pp. 1072-1078, 2012.

[18] R C Bonett, S L T de Souza, A M Batista, J D Szezech Jr, "Super Persistent Transient in A MasterSlave Configuration with Colpitts Oscillator," Journal of Physics A : Mathematicsl and Theoretical, vol. 47, pp. 1-12, 2014.

[19] Mina Shahmohammadi, Masoud Babaie, Robert Bogdan Staszewski, "Tuining Range Extension of A TransformerBased Oscillator Through Common-Mode Colpitts Resonance," IEEE Transaction on Circuits and Systems-I: Regular Papers, vol. 64, no. 4, Apr 2017.

[20] Taylor J, "Harmonic Analysis of RC Active Phase Shift Oscillator," IEEE International Conference on Electronics, Circuits and Systems, 2008, pp. 1131-1134.

[21] Kiani, Mehdi, Ghovanloo, Maysam, "The Circuit Theory Behind Coupled-Mode Magnetic Resonance-Based Wireless Power Transmission," IEEE Transactions on Circuits and Systems I Fundamental Theory and Applications, vol. 59, no. 9, 2012.

[22] Robbin and Miller, Circuit Analysis with Devices: theory \& practice, Thomsen Delmar Learing, 2007.

[23] Wai-Kai Chen, Circuit Analysis and Feedback Amplifier Theory, Taylor \& Francies Group, LLC, CRC press, 2006.

[24] B. L. Theraja, A. K. Theraja, A Textbook of electrical Technology, Volume 1 Basic Electrical Engineering, S. chand \& company Ltd, First Multicolur Edition, New Delhi-India, 2005.

[25] John Brid, Electrical Circuit Theory and Technology, Newnes, British Library, Third Edition 2007.

\section{BIOGRAPHIES OF AUTHORS}

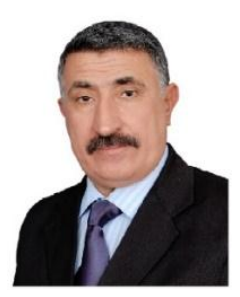

Assistant Professor Khalid Awaad Humood received his bachelor's degree in electronic and communication engineering from Mosul University in 1979. He received a higher diplom degree in electrical engineering / electronic engineering from the University of Technology in 1982 and obtained a master's degree in electrical engineering / electronic engineering from the University of Technology In 1991 and received a Ph. D degree in electrical engineering / electronic engineering from the University of Technology in 2007. He worked as a lecturer at the Rashid College / Technological University for the period 1993-2007. Worked as a lecturer at the Faculty of Engineering / University of Diyala since 2007-. The field of research interest in the analysis and design of systems in the field of electronics engineering and communications. He has more than one scientific research published in local and international magazines Email: humoodkhalid@engineering.uodiyala.edu.iq

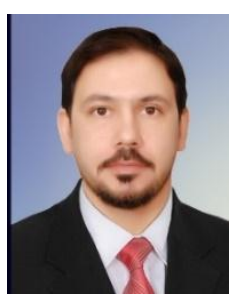

Lecturer Omar Abbood Imran got a master's degree in electrical energy technology from Belgorod State University, Russian Federation in 2013. Currently he works teaching (Assistant Lecturer) at the college of Engineering - University of Diyala since 2013 till now. The field of his research interests is concentrated mainly in the field of electric energy and Electronic and renewable energy. Email : omarimran53@yahoo.com

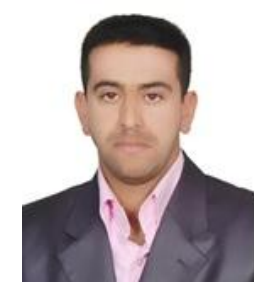

Lecturer Adnan M. Taha got a master's degree in Information technologies and communication systems from $\square$ Kazan National Research Technical University named after A.N. Tupolev, Russian federation, in 2013. Currently he works teaching (Assistant Lecturer) at the college of Engineering University of Diyala since 2013 until now. The field of his research interests in Communication Engineering., electronic Engineering and computer Engineering.

Email : adnanalmamory@gmail.com 